\title{
Characteristics of diffusion-weighted and blood oxygen level-dependent magnetic resonance imaging in Tubulointerstitial nephritis: an initial experience
}

\author{
Tao Su $^{1,2^{*}+} \mathbb{D}$, Xuedong Yang ${ }^{3,4 \dagger}$, Rui Wang ${ }^{3}$, Li Yang ${ }^{1,2^{*}}$ and Xiaoying Wang ${ }^{3}$
}

\begin{abstract}
Background: Diffusion-weighted (DW) and blood oxygen level-dependent (BOLD) magnetic resonance imaging are classical sequences of functional MR, but the exploration in non-transplanted kidney disease is limited. Objects: To analyze the characteristics of apparent diffusion coefficient (ADC) and $R_{2}{ }^{*}$ value using DW and BOLD imaging in tubulointerstitial nephritis (TIN).
\end{abstract}

Methods: Four acute TIN, thirteen chronic TIN patients, and four controls were enrolled. We used multiple gradientecho sequences to acquire $12 \mathrm{~T}^{*}$-weighted images to calculate the $\mathrm{R}_{2}{ }^{*}$ map. DW imaging acquired ADC values by combining a single-shot spin-echo echo-planar imaging pulse sequence and the additional motion probing gradient pulses along the $x, y, z$-axes with two $b$ values:0 and 200, as well as 0 and $800 \mathrm{~s} / \mathrm{mm}^{2}$. ATIN patients performed DW and BOLD magnetic resonance at renal biopsy $\left(T_{0}\right)$ and the third month $\left(T_{3}\right)$. We assessed the pathological changes semiquantitatively, and conducted correlation analyses within functional MR, pathological and clinical indexes.

Results: In ATIN, ADCs were significantly lower( $b$ was $0,200 \mathrm{~s} / \mathrm{mm}^{2}, 2.86 \pm 0.19 \mathrm{vs} .3 .39 \pm 0.11, b$ was $0,800 \mathrm{~s} / \mathrm{mm}^{2}$, $1.76 \pm 0.12$ vs. $2.16 \pm 0.08, P<0.05)$ than controls, showing an obvious remission at $T_{3}$. Cortical and medullary $R_{2}{ }^{*}$ values $\left(\mathrm{CR}_{2}{ }^{*}, \mathrm{MR}_{2}{ }^{*}\right)$ were decreased, significant difference was only observed in $\mathrm{MR}_{2}{ }^{*}\left(T_{0} 24.3 \pm 2.1 \mathrm{vs} . \mathrm{T}_{3} 33.1 \pm 4.1, P<0.05\right)$. No relationship was found between functional MR and histopathological indexes.MR ${ }_{2}^{*}$ had a close relationship with eGFR $(R=0.682, P=0.001)$ and serum creatinine $(R=-0.502, P=0.012)$. Patients with lower $A D C$ when $b$ was $0,200 \mathrm{~s} / \mathrm{mm}^{2}$ showed more increase of $A D C(R=-0.956, P=0.044)$ and $\mathrm{MR}_{2}{ }^{*}(R=-0.949, P=0.05)$ after therapy. In CTIN group, lowered $\mathrm{MR}_{2}{ }^{*}$ and $\mathrm{MR}_{2}{ }^{*} / \mathrm{CR}_{2}{ }^{*}$ provided evidence of intrarenal ischemia. CTIN with advanced CKD (eGFR< 45) had significantly lower $\mathrm{ADC}_{b 200}$ value.

Conclusions: We observed the reduction and remission of ADC and $R_{2}{ }^{*}$ values in ATIN case series. ATIN patients had concurrently decreased $A D C_{b 800}$ and $\mathrm{MR}_{2}{ }^{*}$. The pseudo normalization of $\mathrm{CR}_{2}{ }^{*}$ with persistently low $\mathrm{MR}_{2}{ }^{*}$ in $\mathrm{CTIN}$ suggested intrarenal hypoxia.

Keywords: Magnetic resonance imaging, Diffusion-weighted, Blood oxygenation level-dependent, Tubulointerstitial nephritis, Acute kidney injury, Chronic kidney disease

\footnotetext{
* Correspondence: tao.su@bjmu.edu.cn; li.yang@bjmu.edu.cn

${ }^{\dagger}$ Tao Su and Xuedong Yang contributed equally to this work.

'Renal Division, Department of Medicine, Peking University First Hospital,

Peking University Institute of Nephrology, Beijing, China

Full list of author information is available at the end of the article
}

(c) The Author(s). 2021 Open Access This article is licensed under a Creative Commons Attribution 4.0 International License, which permits use, sharing, adaptation, distribution and reproduction in any medium or format, as long as you give appropriate credit to the original author(s) and the source, provide a link to the Creative Commons licence, and indicate if changes were made. The images or other third party material in this article are included in the article's Creative Commons licence, unless indicated otherwise in a credit line to the material. If material is not included in the article's Creative Commons licence and your intended use is not permitted by statutory regulation or exceeds the permitted use, you will need to obtain permission directly from the copyright holder. To view a copy of this licence, visit http://creativecommons.org/licenses/by/4.0/. The Creative Commons Public Domain Dedication waiver (http://creativecommons.org/publicdomain/zero/1.0/) applies to the data made available in this article, unless otherwise stated in a credit line to the data. 


\section{Background}

Functional magnetic resonance (fMR) imaging has recently grown to be a useful tool to evaluate real-time renal function [1]. The functional MR sequences mainly include blood oxygen level-dependent (BOLD), diffusion-weighted (DW) imaging, arterial labeling perfusion, and dynamic contrast-enhanced imaging. They provide information about diffusion, perfusion, and oxygenation of kidneys besides morphological parameters. In acute kidney injury (AKI) and chronic kidney disease (CKD), these novel techniques have been proposed as promising markers for diagnosis and provide insight into the pathophysiology of kidney disease [2-7]. In the field of kidney transplantation, fMR is recommended as a tool for early differential diagnosis of graft dysfunction $[8,9]$. Researches with fMR were exploratory in animal models and some human observational studies of AKI [10-12], and in CKD patients trying to compare fMR parameters with renal pathological index $[3,10]$. By contrast, fMR imaging's role against pathological findings on non-transplantation human kidney diseases remains poorly understood.

DW and BOLD from magnetic resonance imaging are early used techniques. The total apparent diffusion coefficient (ADC) yielded from DW MR images is influenced by pure diffusion and perfusion-dependent diffusion in the low diffusion weighting ( $b$-value) range. It is regarded as a marker sensitive to alterations in the interstitium, for example, interstitial edema with inflammatory cells infiltration or fibrosis, perfusion, and water handling in the tubular compartment. DW magnetic resonance imaging (MRI) helps diagnose acute renal transplant dysfunction [13]. The ADC value declined with the severity of renal dysfunction and a degree of renal fibrosis after prerenal ischemia-induced AKI [14]. But in another earlier study by Inoue $\mathrm{T}$ et al. [15], they found that neither $\mathrm{ADC}$ values nor $\mathrm{T} 2 *$ values correlated with eGFR in AKI. One possible explanation is that they enrolled complicated pathological types of AKI, including prerenal AKI, acute interstitial nephritis, and glomerulonephritis. Also, studies of ADC values in CKD got conflicting results relating to fibrosis [11].

BOLD MRI provides an index for deoxyhemoglobin levels within a defined volume of tissue (R2*), which was demonstrated to effectively assess changes in intrarenal oxygenation by measuring the $\mathrm{R}_{2}{ }^{*}$ levels of the renal cortex and medulla [10]. The evolution of $\mathrm{R} 2 *$ pre-and post-furosemide injection (renal tubular response to furosemide, evaluated by the furosemide-induced suppression of oxygen consumption, FSOC) was related to impaired renal function [16], being able to make a differentiation between kidneys with preserved tubular function and tubular dysfunction. $\mathrm{Li}$ et al. observed the immediate increase in $\mathrm{R}_{2}{ }^{*}$ in the renal inner stripe of the outer medulla after the injection of contrast agent, suggesting that hypoperfusion probably induced renal hypoxia [17], and BOLD MRI served as a sensitive method for early detection of contrast-induced AKI. Researchers found renal medullary $R_{2}{ }^{*}$ was decreased after furosemide injection In CKD patients with renovascular stenosis due to reduced oxygen consumption of tubular $\mathrm{Na}-\mathrm{K}$ transporter working [18]. While in another report, renal BOLD MR imaging was found not to reflect renal function in CKD [19]. Some researchers recommend direct methods such as phase-contrast MRI to measure renal artery blood flow (RBF) as a surrogate for BOLD. But previous analysis [20] failed to demonstrate associations between $\mathrm{R}_{2}{ }^{*}$ and RBF or sodium absorption, the correlation to RBF was poor, especially in advanced CKD with lower GFR [21]. Therefore, BOLD MRI still has its clinical value in the detection of oxygenation and renal dysfunction.

The pathogenesis of tubulointerstitial nephritis (TIN) lies in damage of tubules, changes of inflammation, edema, or subsequent fibrosis involving corresponding interstitial regions, and following regulation of intrarenal microcirculation. At the same time, glomeruli are initially intact [22]. Besides, tubulointerstitial changes after kinds of glomerular diseases also play a crucial role in disease progression. Therefore, TIN is a perfect disease model for the preliminary study of fMR characteristics in kidney diseases with varied pathological types. The study aimed to observe BOLD and DW magnetic resonance imaging characteristics in patients with acute and chronic tubulointerstitial nephritis.

\section{Methods}

\section{Patients}

Our study included acute tubulointerstitial nephritis (ATIN), chronic tubulointerstitial nephritis (CTIN), and healthy control in a 1: 2: 1 ratio from Jan 2008 to Jan 2009. ATIN patients were included if they (a) were adults diagnosed with biopsy-proven ATIN, (b) were capable of undergoing fMR examination three days within percutaneous renal biopsy, (c) had no signs of other kidney diseases both clinically and pathologically. CTIN patients were selected from our specialty clinic for all-cause tubulointerstitial nephritis (TIN) diseases. Patients were included if they (a) were adults clinically diagnosed with CTIN, (b) clinically had no signs of other kidney diseases and been followed up for more than one year, (c) with a stable serum creatinine level at CKD stage 2-5 [23] and well-controlled hemoglobin level in the recent three months. Healthy volunteers were recruited if they (a) were adults with no history of renal or cardiac diseases and (b) had average serum creatinine concentrations one week before MR scanning. Patients with renal malignancy, malformation, and history of partial nephrectomy were excluded from the study. Patients 
were required not to use diuretics one week before fMR imaging. ATIN patients performed serum creatinine $(\mathrm{SCr})$ and hemoglobulin routinely for six months $\left(\mathrm{T}_{6}\right)$. BOLD and DW imaging was carried out at renal biopsy $\left(\mathrm{T}_{0}\right)$ and the third month after therapy $\left(\mathrm{T}_{3}\right)$.

This prospective study was complied with the declaration of Helsinki and approved by the Human Ethics Committee of Peking University First Hospital. All subjects provided written informed consent and were compatible with MR scanning.

\section{MR imaging}

All patients underwent MR imaging with a 3.0-T MR scanner (General Electric Medical Systems, Milwaukee, WI, USA). A multiple gradient-echo (mGRE) sequence was used to acquire $12 \mathrm{~T} 2$-weighted images to calculate the $\mathrm{R}_{2}{ }^{*}$ map. The parameters of sequence were as follows: TR/TE/Flip angle $/ \mathrm{BW} /$ matrix/ thickness/gap = $100 \mathrm{~ms} / 6.7-32.1 \mathrm{~ms}(12$ echoes $) / 45^{\circ} / 31.3 \mathrm{kHz} / 128 \times 96 / 5$ $\mathrm{mm} / 1 \mathrm{~mm} . \mathrm{NEX}=1$ and five to 6 axial slices were acquired within one breath-hold $24 \mathrm{~s}$. DW imaging was acquired by combining a single-shot spin-echo (SE) echo-planar imaging (EPI) pulse sequence and the additional motion probing gradient (MPG) pulses along the $\mathrm{x}, \mathrm{y}, \mathrm{z}$-axes. The parameters were as follows: TR/TE/ $\mathrm{BW} /$ matrix $=2300 \mathrm{~ms} / 56.1 \mathrm{~ms} / 250 \mathrm{kHz} / 128 \times 128$.

$\mathrm{NEX}=2$ and the slice position were identical to the BOLD imaging by the "copy" function embedded in the MR scanner, which was scanned within $18 \mathrm{~s}$. We used two different b value group: 0 and $200 \mathrm{~s} / \mathrm{mm}^{2}$ as well as 0 and $800 \mathrm{~s} / \mathrm{mm}^{2}$. We acquired axial images for both BOLD and DW images.

Both $\mathrm{R}_{2}$ * map and apparent diffusion coefficient ADC map were generated on an AW 4.2 workstation (General Electric Medical Systems, Milwaukee, WI, USA) using "Functool" software. The reader was blinded to the subject's clinical information. At least eight regions of interest (ROIs), each area of which was at least 10 pixels, were carefully placed on the cortex and medulla on the corresponding anatomical template separately (using image of $\mathrm{TE}=32.1 \mathrm{~ms}$ as a template), the measured slices covered most of the kidney. Because of the low resolution of the images, particularly in severe renal impairment patients, it was impossible to reliably discriminate between the cortex and the medulla, which meant that the ROIs could not be reliably placed. Hence it was only possible to calculate global ADCs for each kidney. The ROIs were manually delineated in the parenchyma of the kidneys. Both $R_{2}{ }^{*}$ and ADC values were read out on the corresponding $\mathrm{R}_{2}{ }^{*}$ and ADC map (Figs. 1-2). The cortical $\mathrm{R}_{2}{ }^{*}\left(\mathrm{CR}_{2}{ }^{*}\right)$, medullary $\mathrm{R}_{2}{ }^{*}$ $\left(\mathrm{MR}_{2}{ }^{*}\right)$, and global ADC of the kidneys were calculated separately for each side.

\section{Pathology}

Renal tissues from four ATIN patients were handled routinely by Haemotoxylin-Eosin, Masson's trichrome, periodic acid-Schiff, and periodic acid-silver methenamine staining for light microscopy examination. The tissue core was often obtained at depths of about $1 \mathrm{~cm}$. The histopathological indexes included tubular injuries (tubular epithelial cells atrophy, vacuolar degeneration, brush border shedding, necrosis, and tubulitis) and interstitial changes (edema, inflammation, and fibrosis). Area and degree of tubular brush border shedding, atrophy, and interstitial change were semiquantitatively assessed as scores 1, 2, 3, and 4 correspondings to not, mild, moderate, and severe changes by two different pathologists referring to a modification of the Banff Working Classification [24, 25]. They were also blind to the clinical data. The activity index (AI) was the total score for tubular injuries, interstitial edema, and inflammatory infiltration. The chronicity index $(\mathrm{CI})$ was the total of the scores for tubular atrophy and interstitial fibrosis.
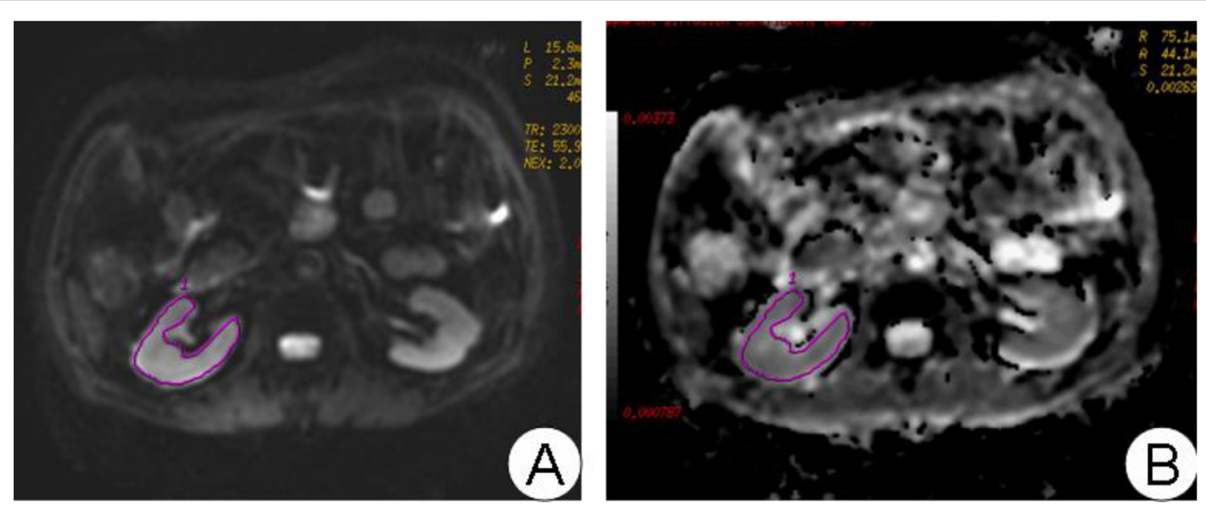

Fig. 1 A: DWI image. B: The corresponding ADC diagram. The method of manual placement of ROI is used to outline the kidney on the anatomical map with DWI 

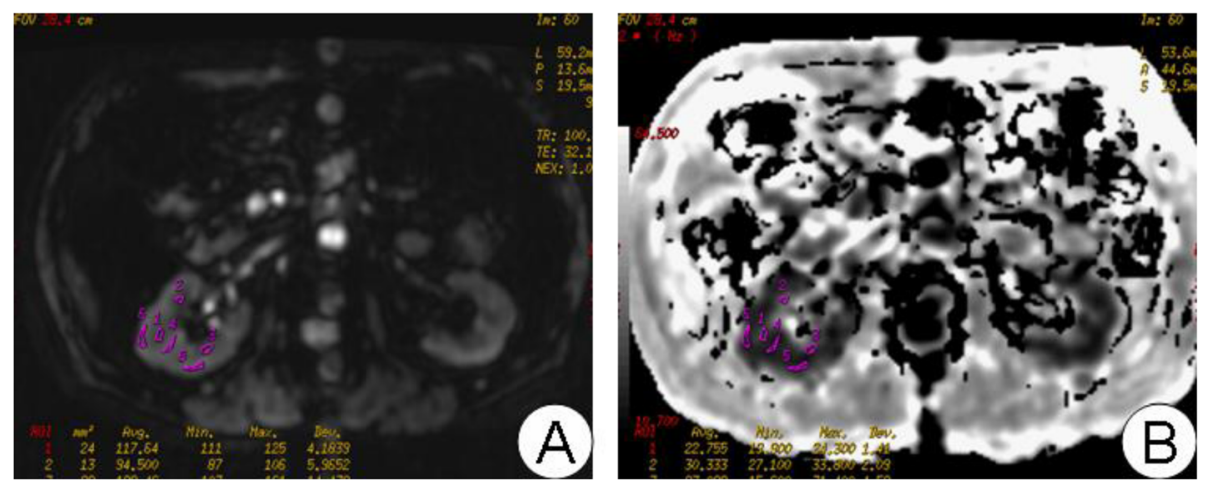

Fig. 2 A: BOLD image anatomical template. B: The corresponding R2* figure. The manually placing $\mathrm{ROI}$ on the anatomical template is to place at least three $\mathrm{ROI}$ in the cortical medulla and read the corresponding $\mathrm{R}^{*}$ value on the corresponding $\mathrm{R} 2^{*}$ diagram

\section{Statistical analysis}

Statistical analyses were performed using the software SPSS Version 20.0 (IBM Corp., Armonk, NY). Data were presented as the median and range. The non-parametric Kruskal-Wallis test analyzed differences between groups. Correlations were assessed according to the Pearson test for parametric data and the Spearman test for nonparametric data. The correlations between serum creatinine, eGFR, albuminuria, and the fMR parameters (kidney volume, ADC value, and $\mathrm{R}_{2}$ * value) of all kidneys were determined. The correlations between pathological indexes and fMR parameters were also analyzed. A Pvalue less than 0.05 was defined as statistically significant.

\section{Results}

\section{Clinical and pathological characteristics}

There were 20 individuals recruited for this study, including 5 ATIN patients, 15 CTIN patients, and five healthy control. Four patients were excluded from the study because their fMR images' quality was poor to be used (Fig. 3. flow chart). Thus, four patients with ATIN, thirteen patients with CTIN, and four healthy control were finally enrolled. The demographic and clinical data of the subjects are summarized in Table 1. The ATIN patients were $43.8 \pm 19.4$ years old, with an average of $52.0 \pm 13.3$ years old of CTIN patients. All the ATIN patients who experienced acute kidney injury (AKI) were

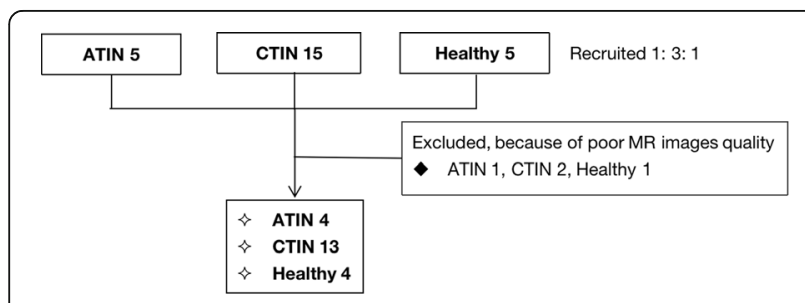

Fig. 3 The flowchart of the study defined using the Kidney Disease: Improving Global Outcomes (KDIGO) [26, 27] criteria and consensus report of the Acute Disease Quality Initiative 16 Workgroup. One patient was in AKI stage 1, two in AKI stage 2 , and one in AKI stage 3. Renal pathology revealed that in ATIN kidneys, the glomeruli were relatively intact. Focal or diffuse tubular injuries, diffuse interstitial edema, and mononuclear cell infiltration were predominant pathological findings (Fig. 4). The activity index was averaged $12.8 \pm 3.3$, with the chronicity index $3.5 \pm$ 0.6. Increased urinary albumin was at an average of $102.0 \pm 65.9 \mathrm{mg} / \mathrm{L}$. The Scr level was $112 \sim 401 \mu \mathrm{mol} / \mathrm{l}$ $\left(217.4 \pm 126.4 \mu \mathrm{mol} / \mathrm{l}\right.$, eGFR $\left.37.4 \pm 31.5 \mathrm{ml} / \mathrm{min} / 1.73 \mathrm{~m}^{2}\right)$ at renal biopsy, and gradually declined to average level after short-term steroids administration during the following three months, the eGFR was averaged $66.6 \pm 31.2$ $\mathrm{ml} / \mathrm{min}, 74.4 \pm 41.1 \mathrm{ml} / \mathrm{min}$ at the third $\left(\mathrm{T}_{3}\right)$ and sixth month $\left(\mathrm{T}_{6}\right)$. The hemoglobulin of ATIN patients was $99.0 \pm 13.4 \mathrm{~g} / \mathrm{L}$ initially and corrected to $129.0 \pm 13.2 \mathrm{~g} / \mathrm{L}$.

Thirteen patients with CTIN were enrolled from our out-patient specialty for tubulointerstitial nephritis under integrative supportive therapy for CKD. The renal function was stable the recent three months before MR imaging. Patients were in CKD stage $2 \sim 5$ non-dialysis, whose eGFRs were averaged $34.7 \pm 21.9 \mathrm{ml} / \mathrm{min}$ (Scr 102 $\sim 526 \mu \mathrm{mol} / \mathrm{l})$. Urinary albumin was $30.0 \pm 17.5 \mathrm{mg} / \mathrm{L}$. Renal anemia of CTIN patients had already been corrected to $126.8 \pm 16.8 \mathrm{~g} / \mathrm{L}$, which was matchable with healthy control.

\section{Functional MR imaging features}

In control kidneys (Fig. 5), the outline was smooth, and there was a clear differentiation between renal cortex and medulla on $\mathrm{T}_{1}$-weighted $\mathrm{SE}$ and $\mathrm{IR}$ sequence. The average volume of kidneys was $(144.6 \pm 16.8) \times 10^{3} \mathrm{~mm}^{3}$. Global ADC values of DW imaging were $3.39 \pm 0.11$ and $2.16 \pm 0.08$, respectively, when the $b$ value was 0,200 , or $0,800 \mathrm{~s} / \mathrm{mm}^{2} . \mathrm{CR}_{2}$ * value yielded from BOLD MRI was 
Table 1 Laboratory and fMR data of ATIN and CTIN kidneys

\begin{tabular}{|c|c|c|c|c|c|c|c|c|c|c|}
\hline & Age & $\begin{array}{l}\text { Scr } \\
(\mu \mathrm{mol} / \mathrm{l})\end{array}$ & $\begin{array}{l}\text { eGFR } \\
\text { (ml/min) }\end{array}$ & $\begin{array}{l}\mathrm{Hb} \\
(\mathrm{g} / \mathrm{L})\end{array}$ & $\begin{array}{l}\mathrm{CR}_{2}{ }^{*} \\
(\mathrm{~Hz})\end{array}$ & $\begin{array}{l}\mathrm{MR}_{2}{ }^{*} \\
(\mathrm{~Hz})\end{array}$ & $\begin{array}{l}\mathrm{CR}_{2}{ }^{*} \\
/ \mathrm{MR}_{2}{ }^{*}\end{array}$ & $\begin{array}{l}A D C \\
\text { value } \\
b \text { value } \\
800 \\
\left(\mathrm{~s} / \mathrm{mm}^{2}\right)\end{array}$ & $\begin{array}{l}A D C \\
\text { value } \\
b \text { value } \\
200 \\
\left(\mathrm{~s} / \mathrm{mm}^{2}\right)\end{array}$ & $\begin{array}{l}\text { Volume } \\
\text { (cm3) }\end{array}$ \\
\hline Control & $50.3 \pm 10.0$ & $72.3 \pm 11.5$ & $98.0 \pm 6.7$ & $135.2 \pm 5.2$ & $\begin{array}{l}19.7 \pm \\
2.1\end{array}$ & $\begin{array}{l}33.1 \pm \\
4.1\end{array}$ & $\begin{array}{l}1.68 \pm \\
0.03\end{array}$ & $2.16 \pm 0.08$ & $3.39 \pm 0.11$ & $\begin{array}{l}144.6 \pm \\
16.8\end{array}$ \\
\hline ATIN TO & $43.8 \pm 19.4$ & $\begin{array}{l}217.4 \pm 126.4(112 \sim \\
401)\end{array}$ & $\begin{array}{l}37.4 \pm 31.5(9.9 \sim ~ \\
82.8)\end{array}$ & $99.0 \pm 13.4$ & $\begin{array}{l}17.6 \pm \\
1.3\end{array}$ & $\begin{array}{l}24.3 \pm \\
2.1 \#\end{array}$ & $\begin{array}{l}1.39 \pm \\
0.13\end{array}$ & $\begin{array}{l}1.76 \pm \\
0.12 \#\end{array}$ & $\begin{array}{l}2.86 \pm \\
0.19 \#\end{array}$ & $\begin{array}{l}176.8 \pm \\
82.8\end{array}$ \\
\hline T3 & & $103.3 \pm 15.8$ & $66.6 \pm 31.2$ & $129.0 \pm 13.2$ & $\begin{array}{l}18.3 \pm \\
2.2\end{array}$ & $\begin{array}{l}32.4 \pm \\
6.6\end{array}$ & $\begin{array}{l}1.8 \pm \\
0.52\end{array}$ & $\begin{array}{l}2.02 \pm \\
0.04^{*}\end{array}$ & $\begin{array}{l}3.41 \pm \\
0.10^{*}\end{array}$ & $\begin{array}{l}154.2 \pm \\
7.0\end{array}$ \\
\hline T6 & & $97.5 \pm 21.0(76 \sim 118)$ & $\begin{array}{l}74.4 \pm 41.1(43.6 \sim \\
132.2)\end{array}$ & $134.8 \pm 8.6$ & N.D. & N.D. & N.D. & N.D. & N.D. & N.D. \\
\hline CTIN & $52.0 \pm 13.3$ & $\begin{array}{l}240.2 \pm 146.0(102 \sim \\
526)\end{array}$ & $\begin{array}{l}34.7 \pm 21.9(5.1 \sim ~ \\
79.8)\end{array}$ & $126.8 \pm 16.8$ & $\begin{array}{l}19.0 \pm \\
2.2\end{array}$ & $\begin{array}{l}28.0 \pm \\
5.0\end{array}$ & $\begin{array}{l}1.32 \pm \\
0.69\end{array}$ & $2.20 \pm 0.20$ & $3.46 \pm 0.43$ & $\begin{array}{l}89.0 \pm \\
23.0 \wedge\end{array}$ \\
\hline $\begin{array}{l}\text { eGFR< } \\
45\end{array}$ & & & & & & & & $2.23 \pm 0.21$ & $\begin{array}{l}3.14 \pm \\
0.30 *\end{array}$ & \\
\hline $\begin{array}{l}\text { eGFR> } \\
45\end{array}$ & & & & & & & & $2.15 \pm 0.19$ & $3.66 \pm 0.37$ & \\
\hline
\end{tabular}

Note: $\mathrm{CR}_{2}{ }^{*}$, Cortical $\mathrm{R}_{2}{ }^{*} ; \mathrm{MR}_{2}{ }^{*}$, Medullary $\mathrm{R}_{2}{ }^{*}$, N.D. no data

\# when compared between T0 and control, the difference is significant $P<0.05$

* when compared between T0 and T3, the difference is significant $P<0.05$

no significant difference was found between T3 and control

※ when compared with group eGFR $>45 \mathrm{ml} / \mathrm{min}$, the difference is significant $\mathrm{P}<0.05$

$\wedge$ when compared with T0, T3 and control, $P<0.005$

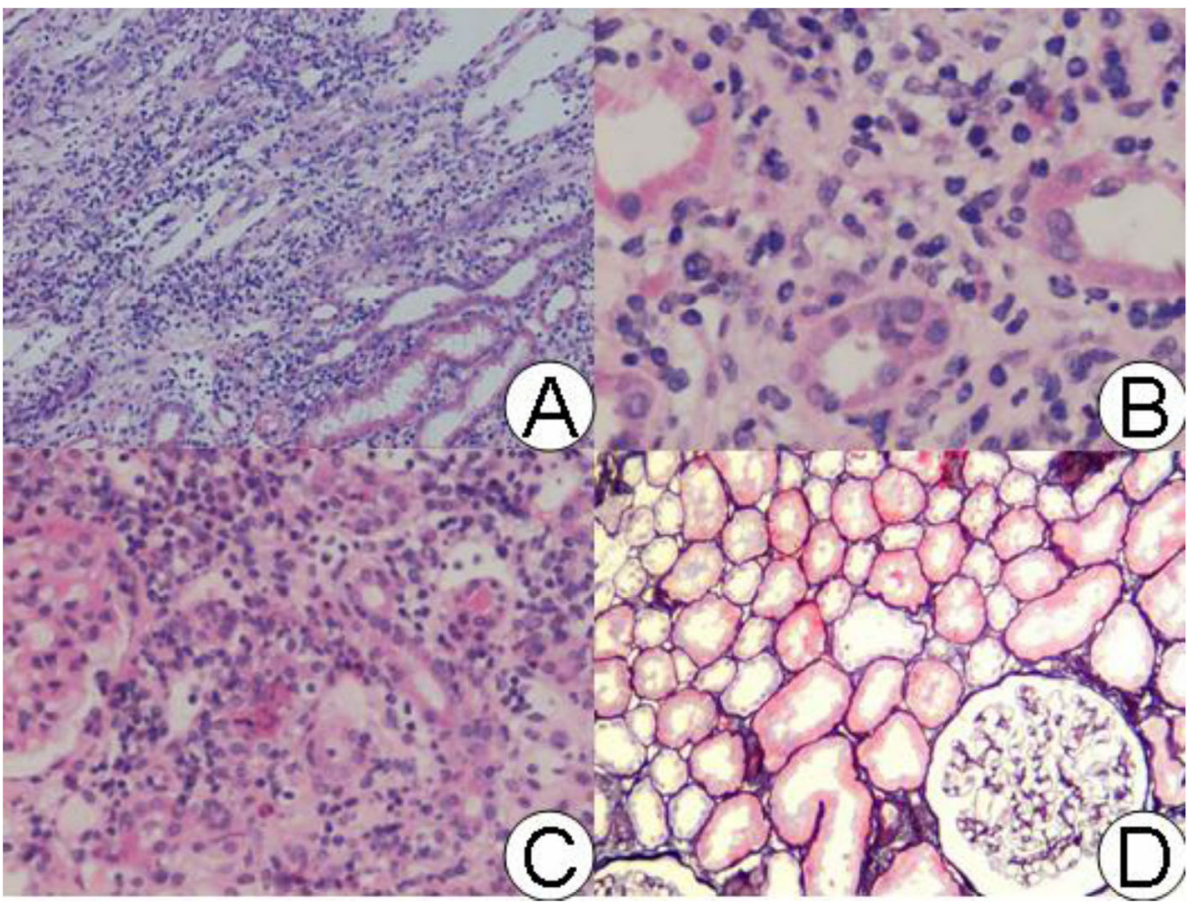

Fig. 4 Pathological pictures of ATIN and normal kidney (all HE staining). A: example 1, magnification 100xdexB: case 2, magnification $\times 400 \times C$ : case 3, magnification $\times 200$. From A to C, ATIN showed exfoliated brush margin of renal tubules, dilated lumen, diffuse edema of the renal interstitium, multifocal or diffuse (C) lymphoid and monocytes infiltration, and eosinophils infiltration. There were no obvious pathological changes in glomeruli and arterioles. Fig. D shows normal kidney, magnification $\times 100$ : glomeruli and tubules are normal 


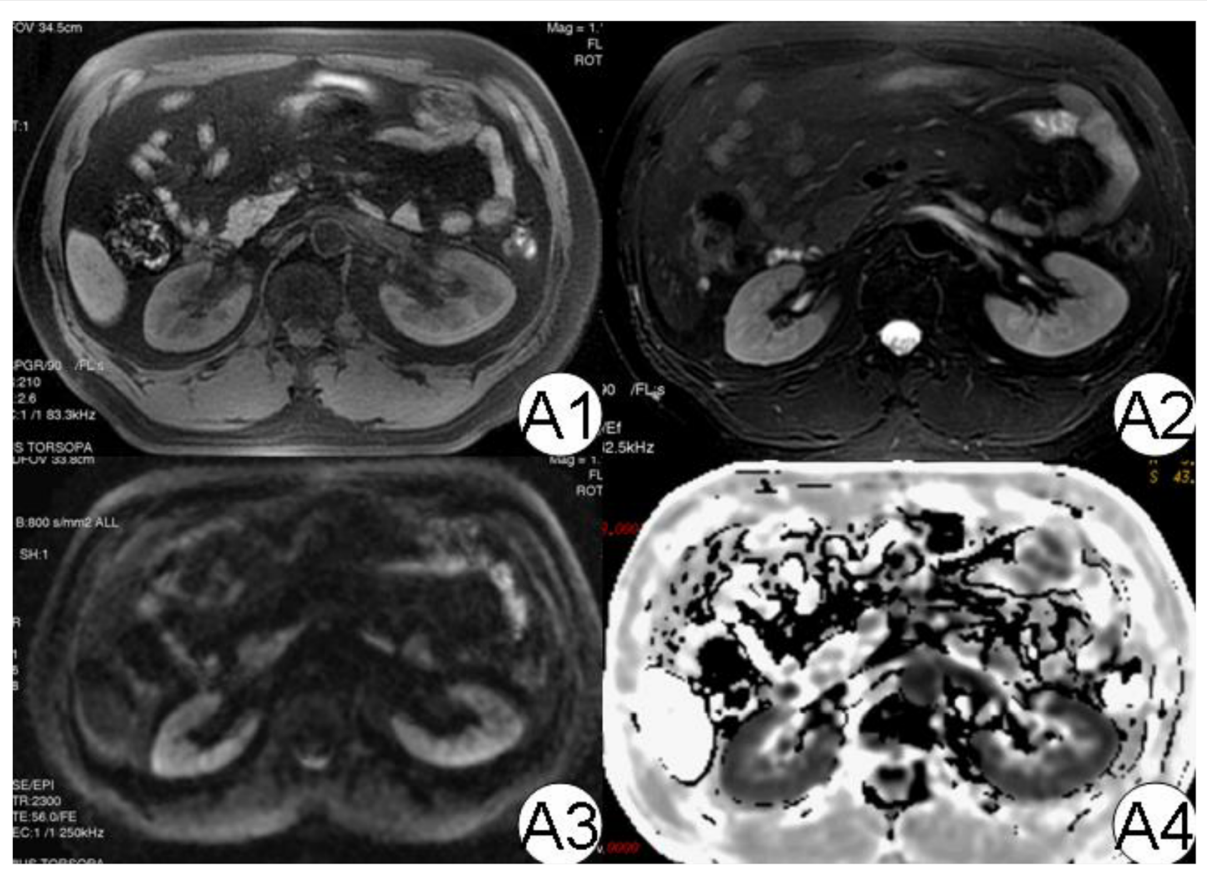

Fig. $5 \mathrm{MRI}$ diagram of normal kidney. In the picture, A1 to A4 are T1WI, T2WI, DWI, and R2*, respectively. It can be seen that the demarcation of the epithelium and medulla on T1WI, T2WI, and R2 * maps is clear (3 points)

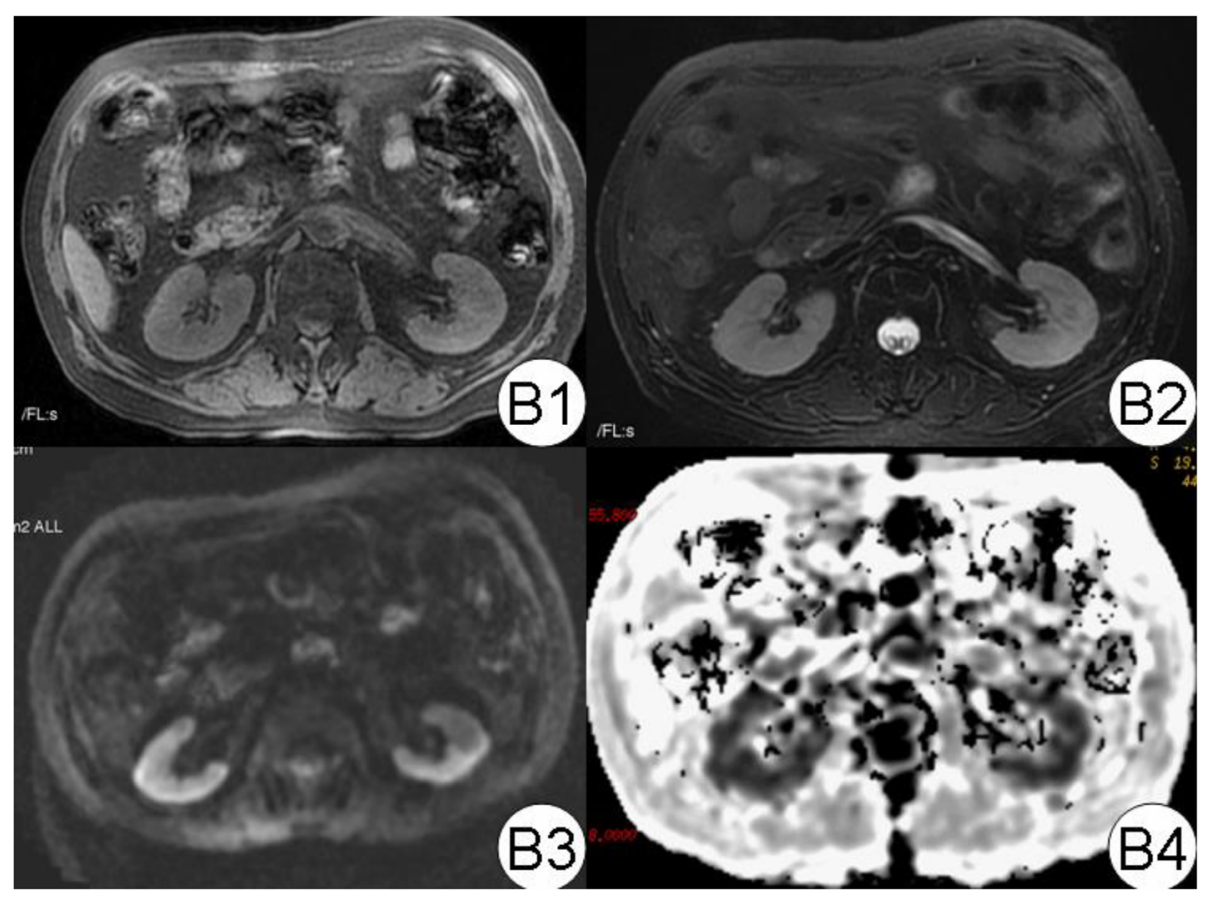

Fig. 6 ATIN kidney MRI diagram. In the picture, B1 to B4 are T1WI and T2WI DWI and R2* pictures, respectively. It can be seen that the

corticomedullary boundary between T1WI and T2WI is OK (2 points). Compared with normal, the cortical area of the R2 * map is slightly irregular 
$19.7 \pm 2.1 \mathrm{~Hz}$, which was lower than medulla [(33.1 \pm 4.1$)$ vs. $(19.7 \pm 2.1) \mathrm{Hz}, p<0.05$ ]. Thus, the ratio of $\mathrm{MR}_{2}{ }^{*}$ to $\mathrm{CR}_{2}{ }^{*}$ was $1.68 \pm 0.03$.

In ATIN patients, swollen kidneys were observed (Fig. 6). The volume was $(176.8 \pm 82.8) \times 10^{3} \mathrm{~mm}^{3}$. ADC values were obtained in DWI both when $b$ value was $0,200 \mathrm{~s} /$ $\mathrm{mm}^{2}$ and $0,800 \mathrm{~s} / \mathrm{mm}^{2}$, and all were found to have significant decreases as $18.5,15.6 \%$ respectively than the control group (Table 1, Figs. 7A-8B). We observed the obvious rising of decreased ADC values following renal function improvement to achieve a $93.5,100 \%$ recovery in the third month (see Table 1). Both $\mathrm{CR}_{2}{ }^{*}$ and $\mathrm{MR}_{2}{ }^{*}$ values of ATIN kidneys were lowered than controls at renal biopsy; the difference was significant in $\mathrm{MR}_{2}{ }^{*}$ values as $26.6 \%$ (difference in $\mathrm{CR}_{2}{ }^{*}$ values was $10.7 \%$ ). The $\mathrm{MR}_{2}{ }^{*}$ values firstly went back to a level similar to control, while the $\mathrm{CR}_{2}$ * values had not yet fully recovered (92.9\% of control). The $\mathrm{MR}_{2}{ }^{*}$ to $\mathrm{CR}_{2}{ }^{*}$ ratio $\left(\mathrm{M} / \mathrm{CR}_{2}{ }^{*}\right)$ was $1.39 \pm 0.13,1.8 \pm 0.52$ respectively, in the acute and remission stage. For CTIN patients (Fig. 8), extremely atrophic kidneys with irregular outlines were found (Fig. 1). The volume was $89.0 \pm$ $23.0 \times 10^{3} \mathrm{~mm}^{3}$. Both ADC values when $b$ values $0,200 \mathrm{~s} /$ $\mathrm{mm}^{2}$ and $b$ value $0,800 \mathrm{~s} / \mathrm{mm}^{2}$ were similar as healthy control. In the $R_{2}{ }^{*}$ map, $M_{2}{ }^{*}$ values of CTIN kidneys were averaged $28.0 \pm 5.0 \mathrm{~Hz}$, which was lower than control, but the difference was not statistically significant. M/ $\mathrm{CR}_{2}{ }^{*}$ ratio was low as $1.32 \pm 0.69$.
Correlation analysis disclosed that neither ADC values nor $\mathrm{R}_{2}{ }^{*}$ values correlated to histopathological indexes, including tubular injuries (tubular epithelial cells atrophy, vacuolar degeneration, brush border shedding, necrosis, and tubulitis) and interstitial changes (edema, inflammation, and fibrosis) when compared separately. We also found no relationship within ADC values, $R_{2}{ }^{*}$ values, $\mathrm{AI}$ and $\mathrm{CI}$. It seems that $\mathrm{ADC}$ and $\mathrm{R}_{2}{ }^{*}$ values changed along with that of renal function (Table 1) in ATIN kidneys, while a close relationship was identified only between $\mathrm{MR}_{2}{ }^{*}$ values and eGFR $(\mathrm{R}=0.8, P=0.017)$, and $\operatorname{Scr}(\mathrm{R}=-0.502, P=0.012)$. The association was similar in CTIN patients $(\mathrm{R}=0.615, P=0.025)$ or all the TIN patients $(\mathrm{R}=0.682, P=0.001$, Fig. $8 \mathrm{~F})$. There was also a correlation between $\mathrm{M} / \mathrm{CR}_{2}{ }^{*}$ and eGFR in the TIN ( $\mathrm{R}=$ $0.659, \mathrm{P}=0.00$ ), but differences were not significant within subgroups (Fig. $8 \mathrm{C}$ ). $\mathrm{ADC}_{b 800}$ was inversely correlated with albuminuria $(\mathrm{R}=-0.951, \mathrm{P}=0.001)$ in ATIN patients, while had no such relationship in CTIN. We noticed that significantly lowered $\mathrm{ADC}_{b 200}$ values occurred in advanced CKD patients with eGFR $<45 \mathrm{ml} / \mathrm{min}$ (when compared with eGFR $>45 \mathrm{ml} / \mathrm{min}: 3.14 \pm 0.30$ vs. $3.66 \pm 0.37, P<0.05)$. We could figure out from Fig. $8 \mathrm{E}$ that ATIN kidneys having relatively lowest $\mathrm{ADC}_{b 800}$ and $\mathrm{MR}_{2} *$ (green dots), distinguished from other diseases. Further analysis revealed that ATIN Patients with lower $\mathrm{ADC}_{b 200}$ were correlated with more $\triangle \mathrm{ADC}_{b 200}$ (the

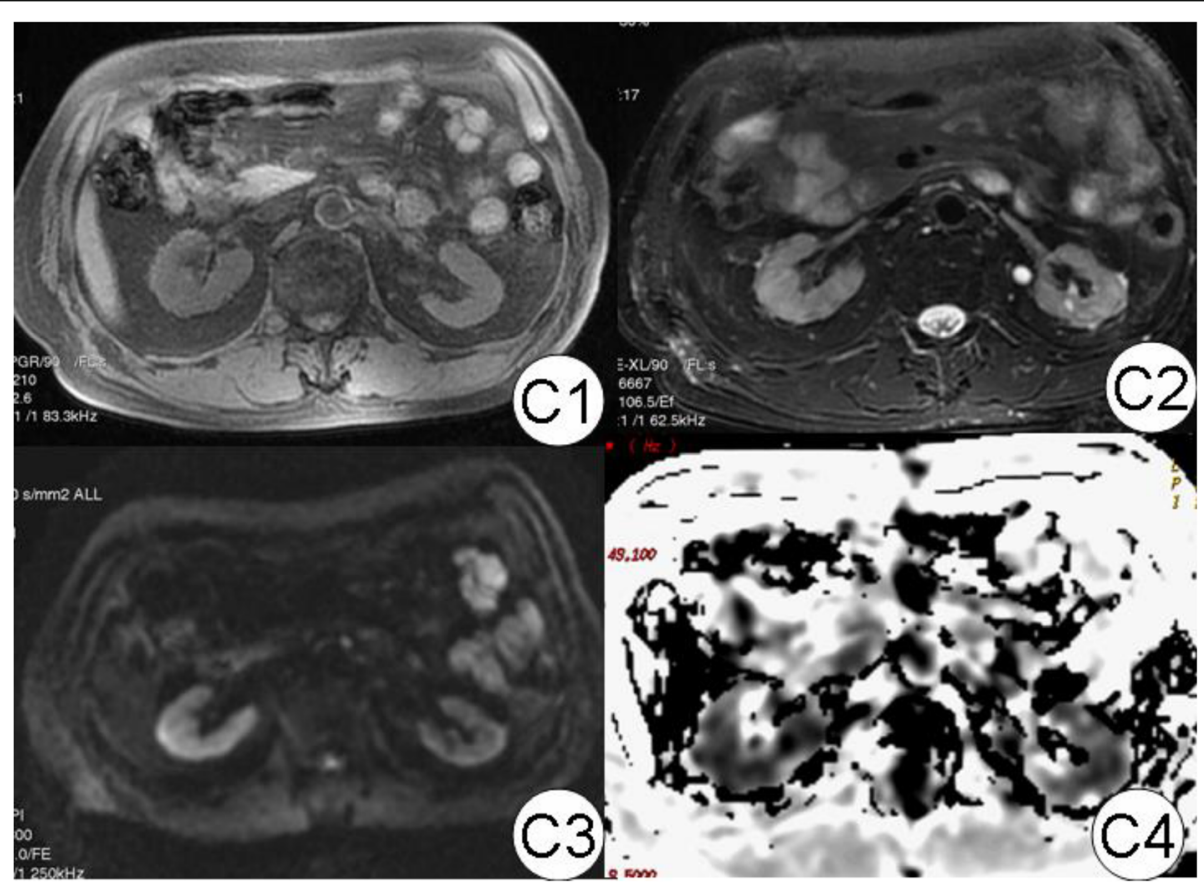

Fig. 7 CTIN kidney MRI diagram. In the figure, C1 to C4 are T1WI and T2WIMagol DWI and R2* pictures, respectively. The epithelial medulla boundary of T1WI and T2WI could only be seen faintly (1 point). When compared with normal and ATIN, the epithelial medulla of R2 * was irregular 


\section{A}

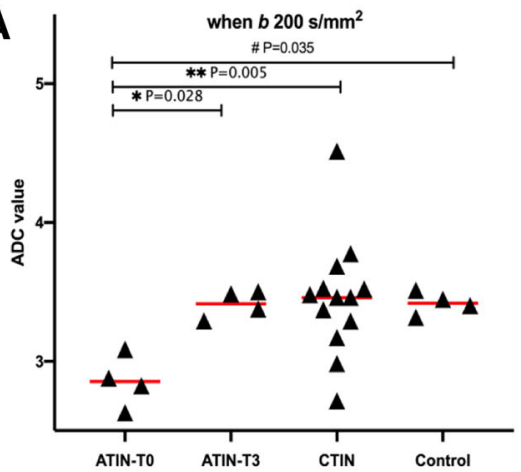

c

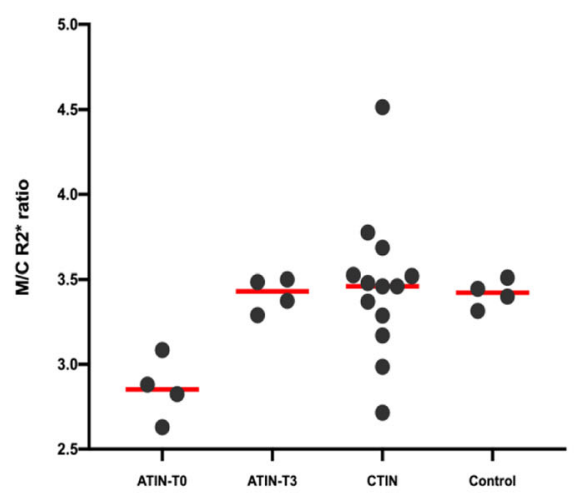

E

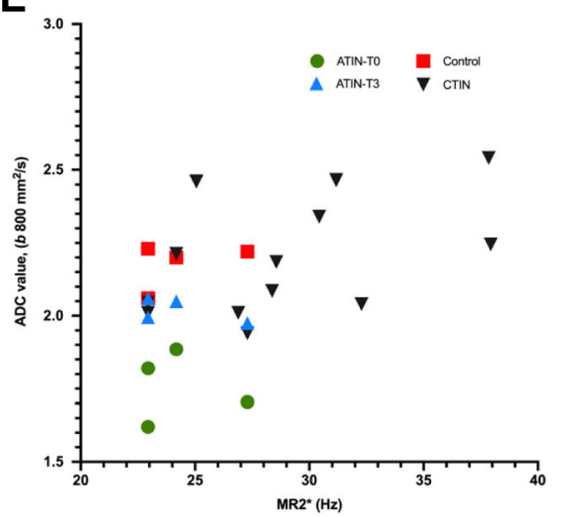

B

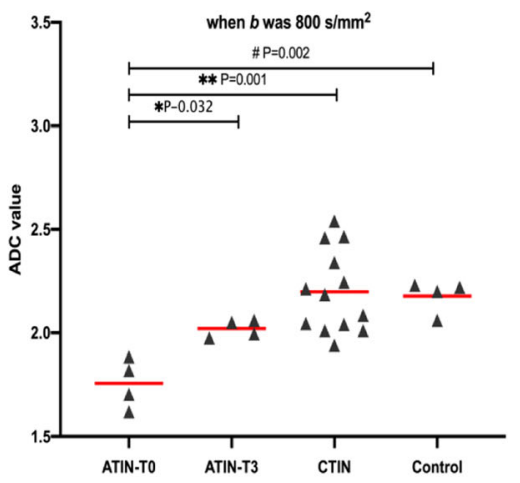

D

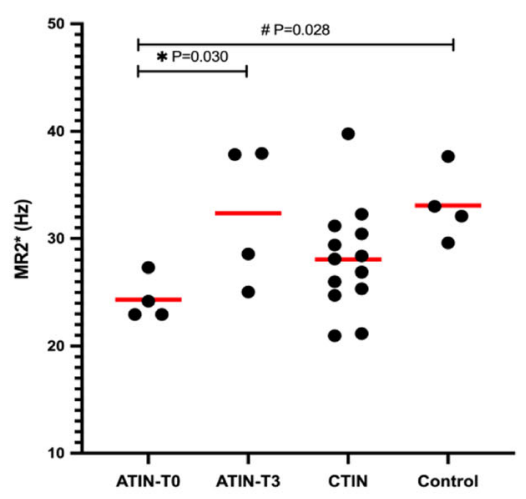

$\mathbf{F}$

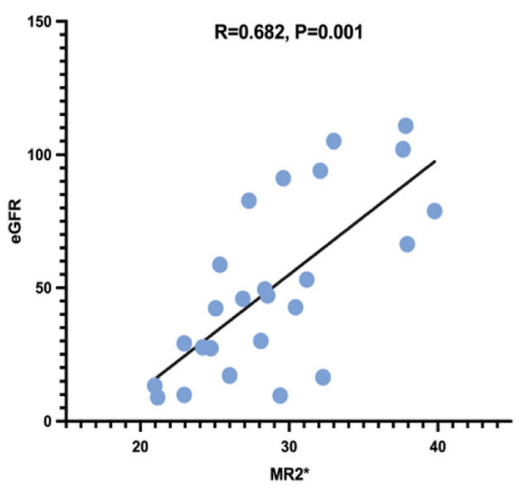

Fig. 8 The correlation analysis of DWI, BOLD parameters and eGFR

increase of $\mathrm{ADC}_{b 200}$ value over the following three months, $\mathrm{R}=-0.956, P=0.044$ ) and $\Delta \mathrm{MR}_{2}{ }^{*}$ (the increase of $\mathrm{MR}_{2}{ }^{*}$ value over the following three months, $\mathrm{R}=$ $0.949, P=0.05)$ after therapy. There was also a relationship between $\triangle \mathrm{ADC}_{b 200}$ and $\Delta \mathrm{MR}_{2}{ }^{*}(\mathrm{R}=0.995, P=$ $0.005)$. However, renal prognosis analysis among candidate predictive markers showed no relationship between time-point $\mathrm{ADC}$ or $\mathrm{R}_{2}{ }^{*}$ values and eGFR. But as $\mathrm{MR}_{2}{ }^{*}$ has a significant correlation to eGFR and Scr levels, it was speculated that a lower $\mathrm{ADC}_{b 200}$ value could predict the degree of $\mathrm{ADC}$ and $\mathrm{MR}_{2}{ }^{*}$ recovery after therapy, which meant a better restoration of renal function.

\section{Discussion}

With MR techniques and clinical applications' developments, it is possible to make a noninvasive assessment of renal pathology types by fMR imaging in patients with kidney diseases. However, at present, there is little evidence directly from kidney histopathology [28-31]. In this study, DW and BOLD MRI parameters of TIN kidneys were acquired and compared between ATIN and CTIN. We also provided sequential changes of fMR in the remission stage of ATIN. By analyzing the correlation of fMR parameters with critical pathological and clinical factors, we explore the potential significance of 
these novel techniques as noninvasive methods, contributing to pathological diagnosis and long-term prognosis assessment, which would enrich our understanding of tubular interstitial diseases.

Diffusion-weighted MR imaging generates the ADC value as an index reflecting the microenvironment of diffusing water molecules. It is considered a simple marker to reflect tissue microstructure. In renal dysfunction, tubular injuries lead to a reduced water reabsorption process resulting in decreased diffusion [32]. Factors involving microcapillary perfusion, the status of tissue edema, and fibrosis also theoretically dedicate to ADC. $\mathrm{Xu} Y$ et al. [33] reported that ADC values of impaired kidneys were significantly lower in a linear but positive correlation with eGFR in CKD patients with renal arterial stenosis. In diabetes nephropathy, ADC values positively correlated to eGFR values, inversely to clinical stages and urinary albumin excretion [34]. But in the AKI study mentioned above [15], neither ADC nor T2* values $(\mathrm{R} 2 *=1 / \mathrm{T} 2 *)$ were correlated with eGFR. One possible explanation is that they enrolled complicated pathological types of AKI, including prerenal AKI, acute interstitial nephritis, and glomerulonephritis. In the current study, there were significantly decreased on initial stage but reversible changes of ADC values in remission (both $b$ values) in ATIN patients self-pre-and posttherapy. The delayed recovery of ADC, especially when $b$ was $0,800 \mathrm{~s} / \mathrm{mm}^{2}$ in the remission stage, meant that kidney injury was still in repair or left behind chronicity. The decrease of ADC ( $b$ was $\left.0,800 \mathrm{~s} / \mathrm{mm}^{2}\right)$ in CTIN patients was mild, suggesting its insensitivity to fibrosis. The finding relationship of albuminuria with $\mathrm{ADC}_{b 800}$ shares the same view of previous studies [34, 35]. Only $\mathrm{ADC}_{b 200}$ served as a factor determined by perfusion and interstitial changes, showed better recognition between mild and severe CKD $($ eGFR $<45)$ in our CTIN patients. This result was in line with a recently published study by Buchanan $\mathrm{CE}$ et al. [36] that ADC differed between low/high interstitial fibrosis groups at $30-40 \%$ fibrosis threshold in CKD. Combined action from concurrent tubular injuries, interstitial inflammation aggravated fibrosis, and intrarenal hypoperfusion in the process of CTIN make the change of ADC value more uncertain. It lacks sensitivity to distinguish edema from fibrosis.

As we have known, the $R_{2}{ }^{*}$ value of BOLD MR imaging has been regarded as a factor reflecting tissue oxygenation [30]. Intrarenal hypoxia contributes to the deterioration of CKD [37]. The changes in cortical oxygenation are usually influenced by nephrotoxicity and severe hemodynamic instability. In a rat model of Gentamycin-induced AKI, only $\mathrm{CR}_{2}{ }^{*}$ was decreased while $\mathrm{MR}_{2}{ }^{*}$ remained constant [38]. This is because gentamycin has direct nephrotoxicity to proximal tubular epithelial cells. The renal medulla is more vulnerable to hypoxia than the cortex because of low oxygen delivery due to low vascular density in the medulla, arterial-venous shunting, and high oxygen consumption for active transcellular transport of sodium in the thick ascending limb of the Henle loop (the target site of inhibitors of the sodium-potassium-chloride cotransporter). A study of the renal response to furosemide showed that medulla oxygenation was increased after furosemide injection while cortical and medullary perfusion remained constant [16]. Renal hypoperfusion leads to a more significant medullary oxygenation change than that of the cortex and medullary perfusion. In the present study, we revealed the close relationship between $\mathrm{MR}_{2}{ }^{*}$ and eGFR. $\mathrm{CR}_{2}{ }^{*}$ and $\mathrm{MR}_{2}{ }^{*}$ were decreased and in remission simultaneously in ATIN, demonstrating that inflammation-relating tubular injury was diffusely distributed in the interstitium. The reduction of $\mathrm{MR}_{2}{ }^{*}$ to $\mathrm{CR}_{2}{ }^{*}$ ratio detected in ATIN and CTIN declared the involvement of ischemic factors leading to tubular injury. Interestingly, $\mathrm{MR}_{2}{ }^{*}$ was persistently low against the "pseudo normalization" of $\mathrm{CR}_{2}$ * with a declining $\mathrm{M} / \mathrm{CR}_{2}{ }^{*}$ ratio, indicated the existence of chronic intrarenal ischemia and hypoxia despite a relatively sufficient oxygen supply than consumption. Intrarenal hypoxia was later emphasized by Sugiyama $\mathrm{K}$ et al. that reduced oxygenation but not fibrosis defined by functional MRI predicts the long-term progression of CKD [39]. From the relationship shown in the scatter plot (Fig. 8E), we observed a concurrently lowered $\mathrm{MR}_{2}{ }^{*}$ with $\mathrm{ADC}_{b 800}$ in ATIN patients [15].

Our study's limitation was the disability to get direct information on intrarenal perfusion. DW and BOLD imaging were the most frequently used fMR imaging techniques in human diseases. Combining these data and developing new strategies would provide more accurate methods to diagnose, assess, and evaluate the mechanism of diseases $[28,29]$. A recent study reported that a combination of renal ADC and parenchymal volume could improve the renal function assessment in CKD [40]. This initial study had limited participants. It is considered more of a proof-ofconcept study, limited to have a definite conclusion with these small numbers. One of the difficulties of patient recruitment in this study lies in that multiparameter sequence MR scanning is inevitably timeconsuming. Furthermore, image quality was enormously influenced by poor respiratory cooperation, which restricts critically ill AKI patients. As a result, fewer patients were suitable for the study, and some patients enrolled were unable to meet the requirements of the study. To make up for these deficiencies, we tried to follow up with these patients and get comparable fMR parameters in the remission stage of ATIN, hoping to give the possible clinical significance of ADC and R2* values. Even so, it was necessary to recruit more participants to verify our results further. 


\section{Conclusions}

This study observed significant reduction and remission of ADC values and $\mathrm{R}_{2}$ * in the ATIN case series. The $\mathrm{ADC}_{b 800}$ and $\mathrm{MR}_{2}{ }^{*}$ were concurrently decreased. Thus, further sample recruitment is essential to verify the diagnosis significance of these functional MR parameters and test sensitivity. The pseudo normalization of $\mathrm{CR}_{2}$ * with persistently lowered $\mathrm{MR}_{2}{ }^{*}$ in CTIN provided evidence of intrarenal hypoxia.

\section{Abbreviations}

MR: magnetic resonance; fMR: functional MR; DW: diffuse weighted BOLD: Blood oxygen level-dependent; ADC: global apparent diffusion coefficient; ATIN: acute tubulointerstitial nephritis; CTIN: chronic tubulointerstitial nephritis; $C R_{2}{ }^{*}$ : cortical $R_{2}{ }^{*}$ values; $M R_{2}{ }^{*}$ : medullary $R_{2}{ }^{*}$ values; $\mathrm{M} / \mathrm{CR}_{2}{ }^{*}$ : the ratio of $\mathrm{MR}_{2}{ }^{*}$ to $\mathrm{CR}_{2}{ }^{*}$

\section{Acknowledgments}

We gratefully thank Dr. Ju Cao and Dr. Gang Liu for their help with data collection, and Dr. Xiaomei Li for the valuable suggestion of project design. We also thank the patients for agreeing to participate in this study.

\section{Authors' contributions}

Tao Su and Xuedong Yang contributed equally to the article. TS and LY contributed to patient diagnosis, management, and clinical data analysis. XY, RW, and XW contributed to functional MR imaging data analysis and provided relating images. TS and XY wrote manuscript drafting, contributed to data analysis, interpretation, and intellectual content of critical importance to the work described. LY and XW interpretation and academic content of crucial importance to the creation and revised the manuscript. All authors had the opportunity to revise the manuscript.

\section{Funding}

This research was supported by grants from National Science and Technology Major Projects for major new drugs innovation and development (2017ZX09304028), the Beijing Young Scientist Program (BJJWZYJH01201910001006), and Peking University Clinical Scientist Program. The funders played roles in collecting data, follow-up of the patients, and interpretation of data.

\section{Availability of data and materials}

These patients were regularly followed up, and the clinical data is traceable. The datasets generated and analyzed during the current study are available from the corresponding author on reasonable request.

\section{Declarations}

\section{Ethics approval and consent to participate}

This prospective study was complied with the declaration of Helsinki and approved by the Human Ethics.

Committee of Peking University First Hospital. All subjects provided written informed consent and were compatible with MR scanning.

\section{Consent for publication}

Not Applicable.

\section{Competing interests}

No one of the authors has a financial and non-financial competing interest.

\section{Author details}

${ }^{1}$ Renal Division, Department of Medicine, Peking University First Hospital, Peking University Institute of Nephrology, Beijing, China. ${ }^{2}$ Renal Pathology Center, Peking University First Hospital, Peking University Institute of Nephrology, Beijing, China. ${ }^{3}$ Department of Radiology, Peking University First Hospital, Beijing, China. ${ }^{4}$ Department of Radiology, Guang'anmen Hospital, China Academy of Chinese Medical Sciences, Beijing, China.
Received: 28 July 2020 Accepted: 9 June 2021

Published online: 29 June 2021

\section{References}

1. Zhang $J$, Rusinek $H$, Chandarana $H$, Lee VS. Functional MRI of the kidneys. J Magn Reson Imaging. 2013;37(2):282-93. https://doi.org/10.1002/jmri.23717.

2. Prasad PV. Functional MRI of the kidney: tools for translational studies of pathophysiology of renal disease. Am J Physiol Ren Physiol. 2006;290:F95874, 5. https://doi.org/10.1152/ajprenal.00114.2005.

3. Caroli A, Schneider M, Friedli I, Ljimani A, De Seigneux S, Boor P, et al. Diffusion-weighted magnetic resonance imaging to assess diffuse renal pathology: a systematic review and statement paper. Nephrol Dial Transplant. 2018:33:ii29-40.

4. Dong J, Yang L, Su T, Yang X, Chen B, Zhang J, et al. Quantitative assessment of acute kidney injury by noninvasive arterial spin labeling perfusion MRI: a pilot study. Sci China Life Sci. 2013;56(8):745-50. https://doi. org/10.1007/s11427-013-4503-3.

5. Zhou HY, Chen TW, Zhang XM. Functional magnetic resonance imaging in acute kidney injury: present status. Biomed Res Int. 2016;2016:2027370.

6. Mao W, Zhou J, Zeng M, Ding Y, Qu L, Chen C, et al. Chronic kidney disease: pathological and functional evaluation with intravoxel incoherent motion diffusion-weighted imaging. J Magn Reson Imaging. 2018:47:11824. https://doi.org/10.1016/j.mri.2017.12.010.

7. Wang ZJ, Kumar R, Banerjee S, Hsu CY. Blood oxygen level-dependent (BOLD) MRI of diabetic nephropathy: preliminary experience. J Magn Reson Imaging. 2011:33:655-60, 3. https://doi.org/10.1002/jmri.22501.

8. Palmucci S, Mauro LA, Veroux P, Failla G, Milone P, Ettorre GC, et al. Magnetic resonance with diffusion-weighted imaging in the evaluation of transplanted kidneys: preliminary findings. Transplant Proc. 2011;43:960-6, 4. https://doi.org/10.1016/j.transproceed.2011.01.157.

9. Yamamoto A, Zhang JL, Rusinek H, Chandarana H, Vivier PH, Babb JS, et al. Quantitative evaluation of acute renal transplant dysfunction with low-dose three-dimensional MR renography. Radiology. 2011;260:781-9, 3. https://doi. org/10.1148/radiol.11101664.

10. Tewes S, Gueler F, Chen R, Gutberlet M, Jang MS, Meier M, et al. Functional MRI for characterization of renal perfusion impairment and edema formation due to acute kidney injury in different mouse strains. PLoS One. 2017;12:1-18.

11. Boor P, Perkuhn M, Weibrecht M, Zok S, Martin IV, Gieseke J, et al. Diffusionweighted MRI does not reflect kidney fibrosis in a rat model of fibrosis. J Magn Reson Imaging. 2015;42:990-8, 4. https://doi.org/10.1002/jmri.24853.

12. Hofmann L, Simon-Zoula S, Nowak A, Giger A, Vock P, Boesch C, et al. BOLD-MRI for the assessment of renal oxygenation in humans: acute effect of nephrotoxic xenobiotics. Kidney Int. 2006:70:144-50, 1. https://doi.org/1 0.1038/sj.ki.5000418

13. Steiger P, Barbieri S, Kruse A, Ith M, Thoeny HC. Selection for biopsy of kidney transplant patients by diffusion-weighted MRI. Eur Radiol. 2017;27: 4336-44, 10. https://doi.org/10.1007/s00330-017-4814-z.

14. Hueper K, Rong S, Gutberlet M, Hartung D, Mengel M, Lu X, et al. T2 relaxation time and apparent diffusion coefficient for noninvasive assessment of renal pathology after acute kidney injury in mice: comparison with histopathology. Investig Radiol. 2013;48:834-42, 12. https://doi.org/10.1 097/RLI.0b013e31829d0414.

15. Inoue T, Kozawa E, Okada H, Inukai K, Watanabe S, Kikuta T, et al. Noninvasive evaluation of kidney hypoxia and fibrosis using magnetic resonance imaging. J Am Soc Nephrol. 2011;22:1429-34, 8. https://doi.org/1 $0.1681 /$ ASN.2010111143.

16. Gomez SI, Warner L, Haas JA, Bolterman RJ, Textor SC, Lerman LO. Romero $J C$ Increased hypoxia and reduced renal tubular response to furosemide detected by BOLD magnetic resonance imaging in swine renovascular hypertension. Am J Physiol Ren Physiol. 2009;297:F981-6, 4. https://doi.org/1 0.1152/ajprenal.90757.2008

17. Li LP, Lu J, Zhou Y, Papadopoulou MV, Franklin T, Bokhary U, et al. Evaluation of intrarenal oxygenation in iodinated contrast-induced acute kidney injury-susceptible rats by blood oxygen level-dependent magnetic resonance imaging. Investig Radiol. 2014:49:403-10, 6. https://doi.org/10.1 097/RLI.0000000000000031

18. Gloviczki ML, Glockner J, Gomez SI, Romero JC, Lerman LO, McKusick M. Textor SC Comparison of 1.5 and 3 T BOLD MR to study oxygenation of kidney cortex and medulla in human renovascular disease. Investig Radiol. 2009;44:566-71, 9. https://doi.org/10.1097/RLI.0b013e3181b4c1e8. 
19. Michaely HJ, Metzger L, Haneder S, Hansmann J, Schoenberg SO, Attenberger UI. Renal BOLD-MRI does not reflect renal function in chronic kidney disease. Kidney Int. 2012;81:684-9, 7. https://doi.org/10.1038/ki.2011.455.

20. Khatir DS, Pedersen $M$, Jespersen B, Buus NH. Evaluation of renal blood flow and oxygenation in CKD using magnetic resonance imaging. Am J Kidney Dis. 2015:663:402-11.

21. Abumoawad A, Saad A, Ferguson CM, Eirin A, Woollard JR, Herrmann SM, et al. Tissue hypoxia, inflammation, and loss of glomerular filtration rate in human atherosclerotic renovascular disease. Kidney Int. 2019;954:948-57.

22. Su T, Gu Y, Sun P, Tang J, Wang S, Liu G, et al. Etiology and renal outcomes of acute tubulointerstitial nephritis: a single-center prospective cohort study in China. Nephrol Dial Transplant. 2018;33:1180-8, 7. https://doi.org/10.1093/ ndt/gfx247.

23. Levey AS, Stevens LA, Schmid CH, Zhang YL, Castro AF, Feldman HI. A new equation to estimate glomerular filtration rate. Ann Intern Med. 2009;150: 604-12, 9. https://doi.org/10.7326/0003-4819-150-9-200905050-00006.

24. Solez K, Colvin RB, Racusen LC, Haas M, Sis B, Mengel M, et al. Valente M Banff 07 classification of renal allograft pathology: updates and future directions. Am J Transplant. 2008;8(4):753-60. https://doi.org/10.1111/j.16006143.2008.02159.x

25. Racusen LC, Solez K, Colvin RB, Bonsib SM, Castro MC, Cavallo T, et al. The Banff 97 working classification of renal allograft pathology. Kidney Int. 1999; 55(2):713-23. https://doi.org/10.1046/j.1523-1755.1999.00299.x.

26. KDIGO AKI Work Group. KDIGO clinical practice guideline for acute kidney injury. Kidney Int Suppl. 2012;17:1-138.

27. Chawla LS, Bellomo R, Bihorac A, Goldstein SL, Siew ED, Bagshaw SM, et al Acute kidney disease and renal recovery: consensus report of the acute disease quality initiative (ADQI) 16 workgroup. Nat Rev Nephrol. 2017;13: 241-57, 4. https://doi.org/10.1038/nrneph.2017.2.

28. Wang W, Yu Y, Wen J, Zhang M, Chen J, Cheng D, et al. Combination of functional magnetic resonance imaging and histopathologic analysis to evaluate interstitial fibrosis in kidney allografts. Clin J Am Soc Nephrol. 2019; 14:1372-80, 9. https://doi.org/10.2215/CJN.00020119.

29. Liang L, Chen WB, Chan KW, Li YG, Zhang B, Liang CH, et al. Using intravoxel incoherent motion MR imaging to study the renal pathophysiological process of contrast-induced acute kidney injury in rats: comparison with conventional DWI and arterial spin labeling. Eur Radiol. 2016;26:1597-605, 6. https://doi.org/10.1007/s00330-015-3990-y.

30. Lang ST, Guo J, Bruns A, Dürr M, Braun J, Hamm B, et al. Multiparametric quantitative MRI for the detection of IgA nephropathy using Tomoelastography, DWI, and BOLD imaging. Investig Radiol. 2019;54:66974, 10. https://doi.org/10.1097/RLI.0000000000000585.

31. Xu X, Palmer SL, Lin X, Li W, Chen K, Yan F, et al. Diffusion-weighted imaging and pathology of chronic kidney disease: initial study. Abdom Radiol (NY). 2018;43:1749-55, 7. https://doi.org/10.1007/s00261-017-1362-6.

32. Morrell GR, Zhang JL, Lee VS. Magnetic resonance imaging of the fibrotic kidney. J Am Soc Nephrol. 2017;28:2564-70, 9. https://doi.org/10.1681/ASN.2 016101089.

33. $X u Y$, Wang $X$, Jiang $X$. Relationship between the renal apparent diffusion coefficient and glomerular filtration rate: preliminary experience. J Magn Reson Imaging. 2007;26:678-81, 3. https://doi.org/10.1002/jmri.20979.

34. Cakmak P, Yağcı AB, Dursun B, Herek D, Fenkçi SM. Renal diffusion-weighted imaging in diabetic nephropathy: correlation with clinical stages of disease. Diagn Interv Radiol. 2014;205:374-8.

35. Chen X, Xiao W, Li X, He J, Huang X, Tan Y, et al. In vivo evaluation of renal function using diffusion weighted imaging and diffusion tensor imaging in type 2 diabetics with normoalbuminuria versus microalbuminuria. Front Med. 2014;84:471-6.

36. Buchanan CE, Mahmoud H, Cox EF, McCulloch T, Prestwich BL, Taal MW, et al. Quantitative assessment of renal structural and functional changes in chronic kidney disease using multi-parametric magnetic resonance imaging. Nephrol Dial Transplant. 2020;35:955-64, 6. https://doi.org/10.1093/ndt/ gfz129.

37. Nangaku M. Chronic hypoxia and tubulointerstitial injury: a final common pathway to end-stage renal failure. J Am Soc Nephrol. 2006;17:17-25, 1. https://doi.org/10.1681/ASN.2005070757.

38. Cao J, Yang XD, Wang XY, Qu L, Liu G, Li XM. Differential changes of intrarenal oxygenation in rat models of acute tubular necrosis caused by aristolochic acid and gentamicin. Zhonghua Yi Xue Za Zhi. 2010;90:1208-12 17.

39. Sugiyama K, Inoue T, Kozawa E, Ishikawa M, Shimada A, Kobayashi N, et al. Reduced oxygenation but not fibrosis defined by functional magnetic resonance imaging predicts the long-term progression of chronic kidney disease. Nephrol Dial Transplant. 2020;35:964-70, 6. https://doi.org/10.1093/ ndt/gfy324.

40. Li Q, Wang D, Zhu X, Shen K, Xu F, Chen Y, et al. Combination of renal apparent diffusion coefficient and renal parenchymal volume for better assessment of split renal function in chronic kidney disease. Eur J Radiol. 2018;108:194-200. https://doi.org/10.1016/j.ejrad.2018.10.002.

\section{Publisher's Note}

Springer Nature remains neutral with regard to jurisdictional claims in published maps and institutional affiliations.
Ready to submit your research? Choose BMC and benefit from:

- fast, convenient online submission

- thorough peer review by experienced researchers in your field

- rapid publication on acceptance

- support for research data, including large and complex data types

- gold Open Access which fosters wider collaboration and increased citations

- maximum visibility for your research: over $100 \mathrm{M}$ website views per year

At BMC, research is always in progress.

Learn more biomedcentral.com/submissions 